\title{
Failure Prediction of Cross-Ply Laminated Double-Serial Mechanically Fastened Composites using Fuzzy Expert System
}

\author{
Serkan Balli1,* - Faruk Sen² \\ ${ }^{1}$ Muğla Sitkı Koçman University, Faculty of Technology, Department of Information Systems Engineering, Turkey \\ 2 Muğla Sitkı Koçman University, Faculty of Technology, Department of Energy Systems Engineering, Turkey
}

The scope of this study is to create a model that predicts failure loads for mechanically fastened composite plates using a fuzzy expert system. The composite material used in the study was manufactured in both a fibre reinforced manner and with glass fibres. The results of a previous experimental study for cross-ply laminated composite plates that were mechanically fastened with two serial pins or bolts were used to model and predict of failure loads. Furthermore, experimental data of a preceding study were obtained with different geometrical parameters for various applied preload moments (pinned/bolted) as 2, 3, 4 and $5 \mathrm{Nm}$. In this study, a fuzzy expert system and regression analysis methods were applied by using these geometrical parameters and pinned/bolted joint configurations. Therefore, 5 geometrical parameters and 300 test data were used. According to obtained results, it was determined that the fuzzy expert system was more appropriate than the regression analysis method for modelling and prediction. Performances of the fuzzy expert system and regression analysis method were discussed in terms of error ratios and mean absolute deviations.

Keywords: fuzzy expert system, bolted joint, pinned joint, fastened joint, laminated composites, fuzzy logic

Highlights

- $\quad$ Predicting failure loads for mechanically fastened composite plates using fuzzy expert system and regression analysis.

- Using composite material manufactured in both a fibre reinforced manner and with glass fibres.

- $\quad$ Creating a expert system model for prediction by applying fuzzy rules and fuzzy membership functions.

- Determination of more appropriate method for modelling and predicting of failure loads.

\section{INTRODUCTION}

Composite materials have been in existence for many centuries; no record exists as to when people first started using them. There are numerous other examples of both natural and man-made composite materials [1]. The improvement of advanced composite materials has in materials applications has been revolutionary in recent years. They are being increasingly utilized in numerous fields, including both military and commercial aerospace applications, as well as the sporting goods and chemical industries [2]. Fiber-reinforced composite materials consist of fibres of high strength and modulus embedded in or bonded to a matrix with distinct interfaces between them. Generally, fibres are the principal load-carrying members, whereas the surrounding matrix keeps them in the preferred position and orientation, acts as a load transfer medium between them and protects them from environmental damage owing to elevated temperatures and humidity [3]. Laminated composite materials consist of layers of at least two different materials that are bonded together. Lamination is used to combine the best aspects of the constituent layers and bonding material in order to achieve a more useful material [4].

Laminates, like many structures, must have holes to serve various purposes. An obvious purpose is to accommodate a bolt [4]. Cutting the fastener holes causes local damage and stress concentrations, and leads to a loss of structural strength. For the design of composite joints with fastener holes, therefore, failure analyses around the fastener holes are critical [5]. A structural joint represents a critical element in the step of the design. In all cases, a significant weight penalty is incurred by the presence of joints in composite structures; furthermore, premature failures have been experienced too frequently [6]. A large part of the research that has been done on mechanically fastened joints has been concerned with the experimental determination of the influence of geometric factors on the joint strength [7].

Wu and Hahn [8] examined the bearing properties of mechanically fastened glass-fibre/vinyl-ester composite joints. Two glass composites of different fabrics and lay-ups were fabricated using vacuumassisted resin-transfer molding (VARTM) and tested using a double-lap joint arrangement. Pakdil et al. [9] determined the influence of preload moments on the failure of glass-epoxy laminated composite single bolted-joints with bolt/hole clearance. In order to observe the effects of bolted-joint geometry and the stacking sequence of laminated plates on the bearing strength and failure mode, parametric analysis was applied, experimentally. Ataş et al. [10] attempted 
to achieve failure load and modes of laminated glass-polyester composite plates using two parallel circular holes, which were exposed to traction forces by two rigid pins. The behaviours of pin-loaded composite plates were observed both experimentally and numerically with different geometries and fibre orientations. Sen and Sayman [11] performed an experimental failure analysis with two serial bolted composite plates. The composite plates were produced from eighth laminas and glass fibres were used as reinforcement material with an epoxy matrix. The effects of the material parameters and design parameters were considered.

Sen et al. [12] investigated the improvement of an artificial neural network (ANN) method for the prediction of bearing strength of two serial pinned/ bolted E-glass reinforced epoxy composite joints. Comparisons of ANN results with desired values showed that there is a good agreement between input and output variables of the experimental data. Chakraborty [13] performed an ANN model-based delamination prediction in laminated composites. It was determined that neural networks were capable of learning the information regarding embedded delamination in a fibre-reinforced plastic laminate. $\mathrm{Li}$ et al. [14] used two-dimensional FEM analysis for deterministic progressive failure analysis. Three groups of failure criteria, three sets of degradation rules and two kinds of shear relationship are employed for progressive damage analysis to predict the mean, the coefficient of variation (COV), and the cumulative distribution function (CDF) of its bearing strength.

In this study, a new approach was performed to predict failure loads of cross-ply laminated doubleserial mechanically fastened composites via a fuzzy expert system. Computational experiments were carried out to predict the behaviour of crossply laminated two serial mechanically fastened composites by using both a fuzzy expert system and regression analysis methods. The performance of both methods was discussed in terms of coefficients of determination, mean absolute deviations, and mean absolute percent deviations.

\section{MECHANICALLY FASTENED COMPOSITE JOINT}

All specifics of the analysed cross-ply composite materials used for this study and the experimental technique were presented in the preceding study by Sen [15]. In brief, rectangular laminated composite specimens manufactured with epoxy and glass fibres with two serial circular holes, and two rigid pins/ bolts were used during experiments. The diameter of each hole $(D)$ was set as $5 \mathrm{~mm}$. The outer hole was positioned along the centerline of the plate at a distance $\mathrm{E}$ from one end of the specimen. The inner hole was placed at a distance $\mathrm{K}$ from the centre point of the outer hole. As a result, the edge distance-tohole diameter ratio $(E / D)$ was as $1,2,3,4$ and 5 . The plate width-to-hole diameter ratio $(W / D)$ was set as 2, 3, 4 and 5 . The distance between two serial holesto-hole diameter ratio $(K / D)$ was as 3,4 and 5 . The total size $(L+K+E)$ of each specimen was $135 \mathrm{~mm}$. The dimension of a specimen is plotted in Fig. 1. Laminated composite specimens were produced from eight unidirectional laminas for arranged stacking sequences as $\left[0 / 0 / 90 / 90^{\circ}\right] \mathrm{s}$. A uniform tensile load $\mathrm{P}$ was applied to the specimens via rigid pins/bolts.
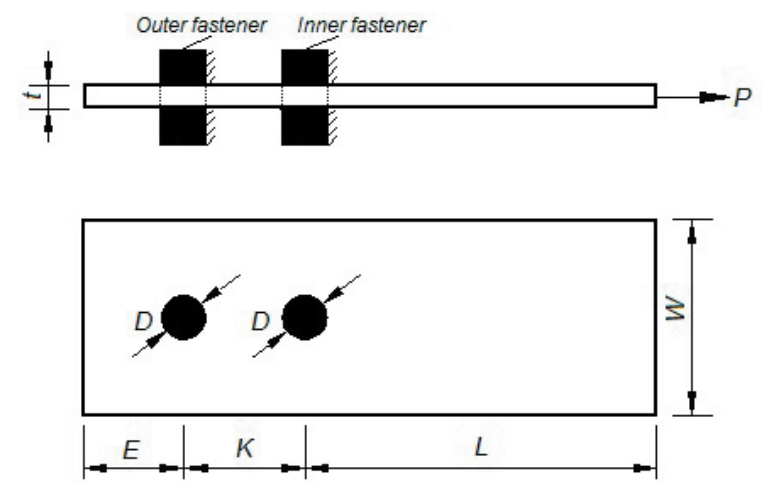

Fig. 1. Dimensions of a laminated composite plate with two serial fasteners

\section{FUZZY LOGIC AND FUZZY EXPERT SYSTEM}

In daily life, people rely on their common sense and use many ambiguous and unclear linguistic terms. The fuzzy set approach can be utilized to represent linguistic terms in the form of numbers [16]. In general, fuzzy sets used to show uncertain information or the structure of a preference were developed by Zadeh [17]. Fuzzy data enable more flexible presentation; with the use of fuzzy data, more sensitive results can be obtained [18]. For each criterion and alternative, the decision maker can use linguistic describers such as good, better or small, very small, etc. depending on his/her preferences [19]. Fuzzy presentation of these linguistic terms is determined according to membership functions. Though there are different types of membership functions used, the most commonly used ones are sigmoid and triangular types, which are presented in Figs. 2 and 3, respectively [20]. For individuals analysed according to determined membership functions, membership values for the 
given criterion are obtained between the ranges of $[0$, $1]$.

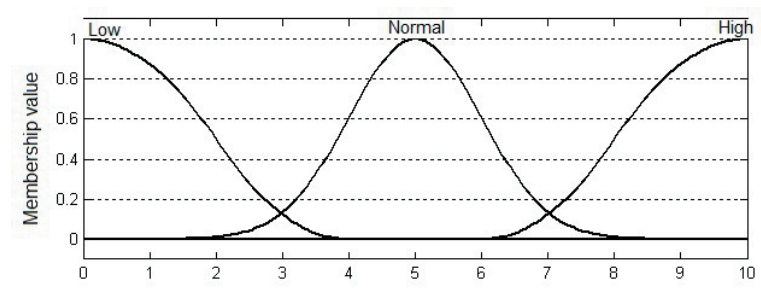

Fig. 2. Sigmoid membership function

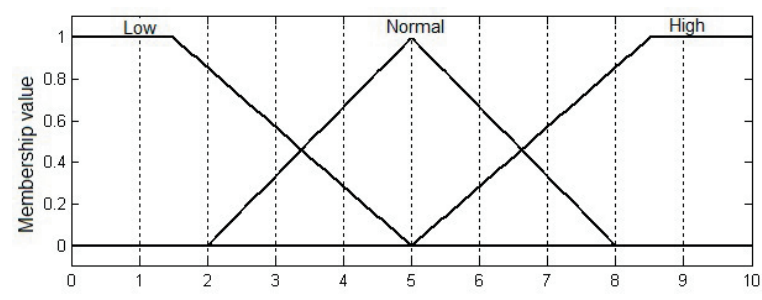

Fig. 3. Triangular membership function

Fuzzy expert systems developed based on fuzzy logic perform reasoning by using numerical operations rather than symbolic reasoning, so they are differentiated from traditional expert systems [21]. With the use of fuzzy logic in expert systems, effectiveness is increased, and response time is decreased [22].

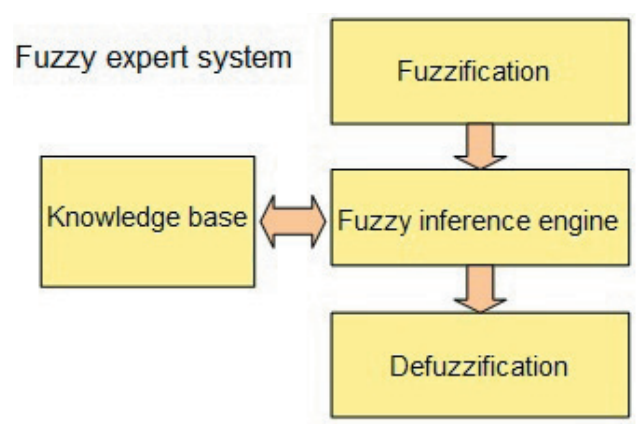

Fig. 4. Structure of fuzzy expert system

As shown in Fig. 4, a fuzzy expert system consists of fuzzification, a knowledge base, a fuzzy inference engine and defuzzification components [23]. The functioning of these components is summarized below:

Fuzzification: Input values are converted into fuzzy values depending on the determined membership function.

Knowledge Base: This is constructed with expert knowledge in application field. The relationships and rules between the input and output values are determined.
Fuzzy inference engine: In light of expert knowledge-based rules, inferences are made from the available information. One of the most widely used methods of inference is Mamdani-style inference [24] because it is more intuitive and closer to human behaviour. In Mamdani-style inference, the existing rules are combined by exposing them to Max-Min operation.

Defuzzification: The operation performed to convert fuzzy information into a particular value is called defuzzification [25]. There are many defuzzification methods, e.g. centroid method, weighted mean method, etc. [20]. In cases in which the membership function is single, the weighted mean method is preferred as it is less complex and easier to calculate in comparison to other methods [26]. It is calculated according to the following equation:

$$
u_{c}=\frac{\sum_{i} \mu_{F}\left(u_{i}\right) \times u_{i}}{\sum_{i} \mu_{F}\left(u_{i}\right)},
$$

where $u_{i}$ represents membership value of the $i^{\text {th }}$ element and $u_{C}$ represents outcome value.

\section{RESULTS}

In this study, the results of previous experimental study [15] that were obtained for cross-ply laminated composite plates mechanically fastened with two serial pins or bolts were used. For the 5 parameters mentioned in Section 2 and concerning the 300 data points, descriptive statistics are presented in Table 1.

Table 1. Descriptive statistics

\begin{tabular}{lccccc}
\hline & Mean & $\begin{array}{c}\text { Standard } \\
\text { deviation }\end{array}$ & Min & Max & Range \\
\hline$M[\mathrm{Nm}]$ & 2.80 & 1.72 & 0 & 5 & 5 \\
\hline$W / D[\mathrm{~mm} / \mathrm{mm}]$ & 3.50 & 1.12 & 2 & 5 & 3 \\
\hline$E / D[\mathrm{~mm} / \mathrm{mm}]$ & 3 & 1.42 & 1 & 5 & 4 \\
\hline$K / D[\mathrm{~mm} / \mathrm{mm}]$ & 4 & 0.82 & 3 & 5 & 2 \\
\hline$F[\mathrm{~N}]$ & 5447 & 1794 & 2108 & 9471 & 7364 \\
\hline
\end{tabular}

The parameters are linear dependent [27] and the data were analysed according to traditional linear regression analysis and fuzzy expert system methods.

Calculated regression function:

$$
F=-810+481 M+995 W / D+340 E / D+103 K / D
$$

Error distribution graph for regression estimate is presented in Fig. 5. The performance of the regression analysis is given in Fig. 6. 


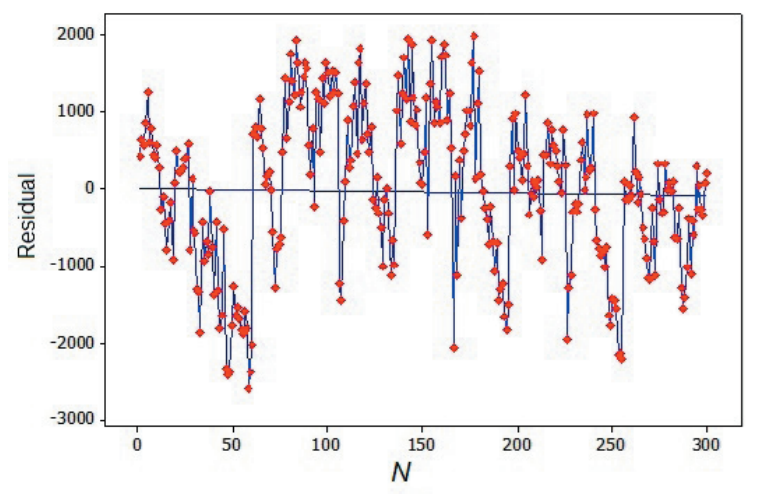

Fig. 5. Error distribution of regression estimate



Fig. 6. Performance of regression estimate

Fuzzification of the data for the fuzzy expert system was performed in line with the membership function shown in Fig. 7. Membership values are in the range of $[0,1]$. There are three different fuzzy sets: low, medium and high. For the output value $F$, the membership function is given in Fig. 8. There are five different fuzzy sets for $F$.

The values for parameters were determined by considering membership functions. These values were expressed in linguistic terms and then entered into the knowledge database, and 10 sample values selected out of 300 values are presented in Table 2.

In line with the data collected thus far, an evaluation model in Matlab environment was constructed as shown in Fig. 9 by using expertise and information for reasoning and inference.

As the fuzzy inference engine consists of four criteria and three fuzzy sets belonging to each criterion, it consists of $3^{4}$ rules. The rules are constructed in line with expert knowledge and experience. In general, the weights of all rules are equal but particular weight can be attached to specific rules determined according to the expert.

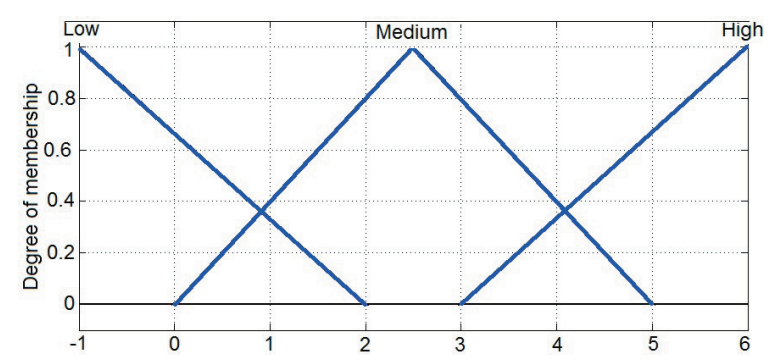

Fig. 7. Membership function for $M, W / D, E / D$

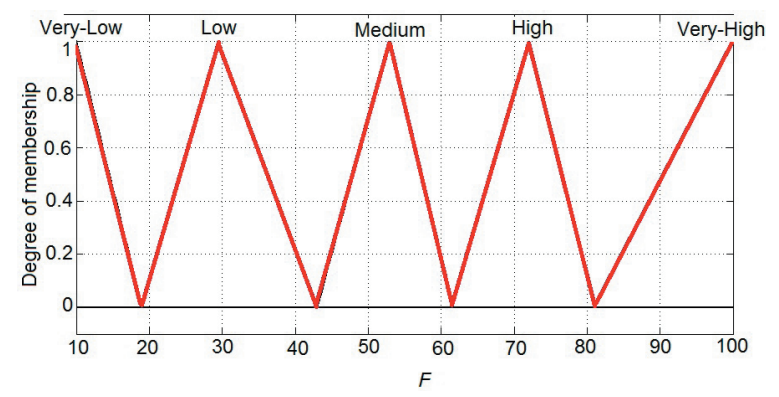

Fig. 8. Membership function for $F$

Table 2. Linguistic fuzzy values for the parameters

\begin{tabular}{cccc}
\hline$M$ & $W / D$ & $E / D$ & $K / D$ \\
\hline Low & High & Medium & Low \\
\hline Medium & Low & High & Medium \\
\hline High & Medium & Low & High \\
\hline Low & Low & High & Medium \\
\hline High & High & Medium & Low \\
\hline High & Low & Low & Medium \\
\hline Medium & Low & Medium & Medium \\
\hline Medium & Medium & Medium & Medium \\
\hline Low & Medium & Medium & Medium \\
\hline Medium & High & High & High \\
\hline
\end{tabular}



System model: 4 inputs, 1 output, 81 rules

Fig. 9. Fuzzy expert system 
Some of these rules are:

IF ( $M$ is Low) and ( $W / D$ is Low) and $(E / D$ is Low) and $(K / D$ is Low) then ( $F$ is Very-Low),

IF ( $M$ is Low) and ( $W / D$ is Medium) and $(E / D$ is Low) and $(K / D$ is Medium) then ( $F$ is Low),

IF ( $M$ is Low) and ( $W / D$ is High) and ( $E / D$ is Low) and $(K / D$ is High) then ( $F$ is Medium),

IF ( $M$ is High) and ( $W / D$ is Medium) and $(E / D$ is High) and (K/D is Medium) then ( $F$ is High),

IF ( $M$ is High) and (W/D is High) and ( $E / D$ is High) and ( $K / D$ is High) then ( $F$ is Very-High).

The rules are constituted by linguistic values. The $F$ value changes depending on other parameter's status when they are examined. In Figs. 10 to 21, rule surfaces showing three-dimensional input-output relationship for $F$ corresponding to the parameters according to all the rules are presented.

In Fig. 22, the error distribution graph for predictions made according to fuzzy expert system is given. In Fig. 23, the performance graph of fuzzy expert system is seen.

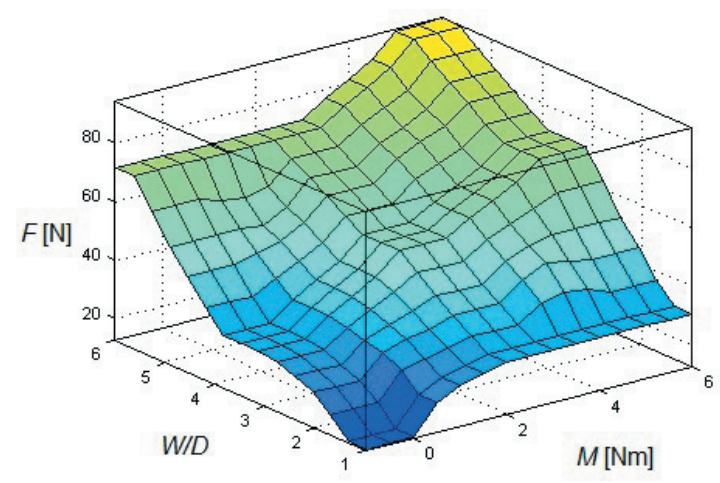

Fig. 10. Surface plot of $F$ and $M ; W / D$

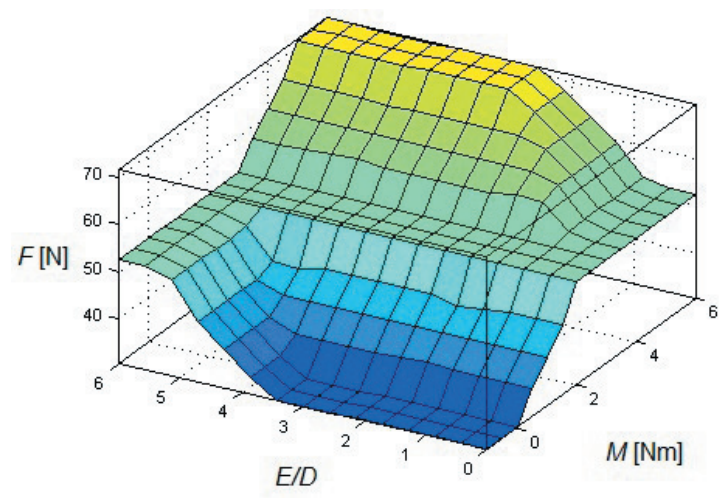

Fig. 11. Surface Plot of $F$ and $M ; E / D$

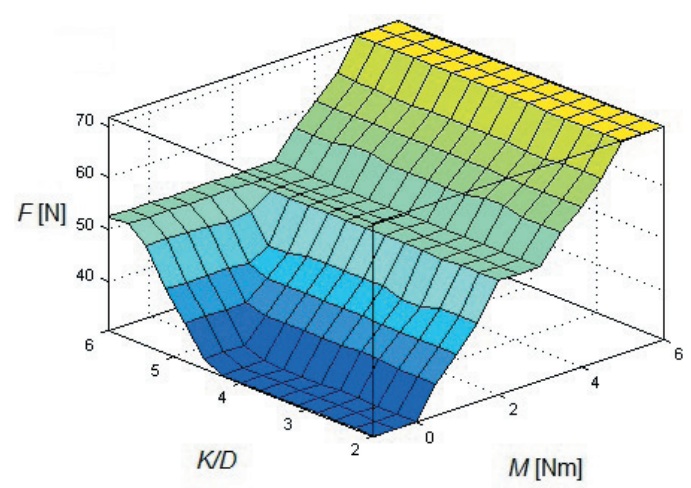

Fig. 12. Surface plot of $F$ and $M ; K / D$

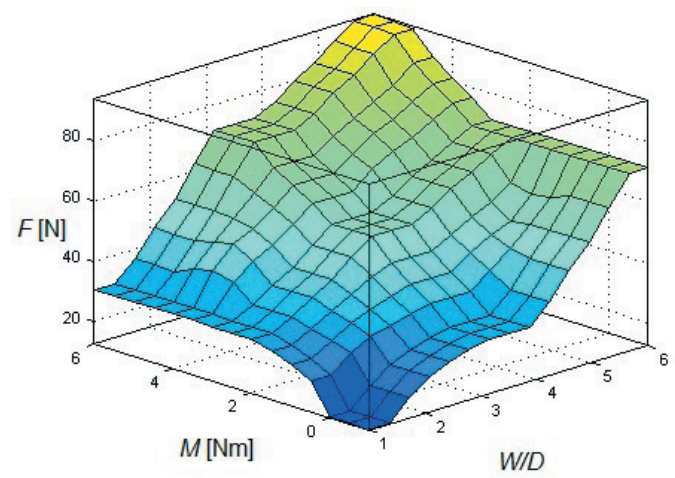

Fig. 13. Surface plot of $F$ and $W / D ; M$

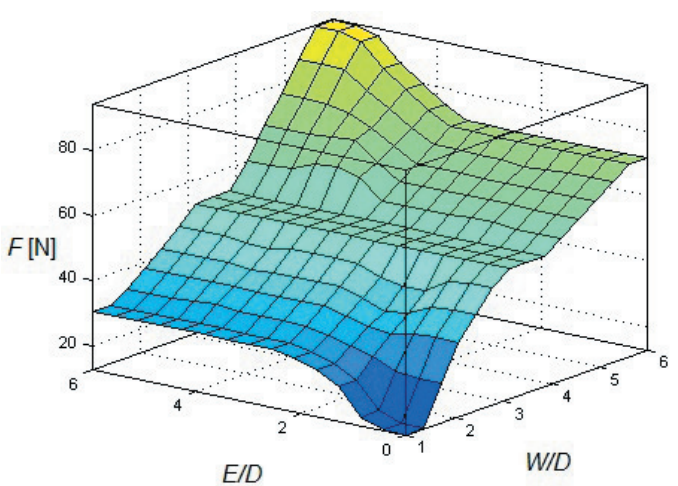

Fig. 14. Surface plot of $F$ and $W / D ; E / D$

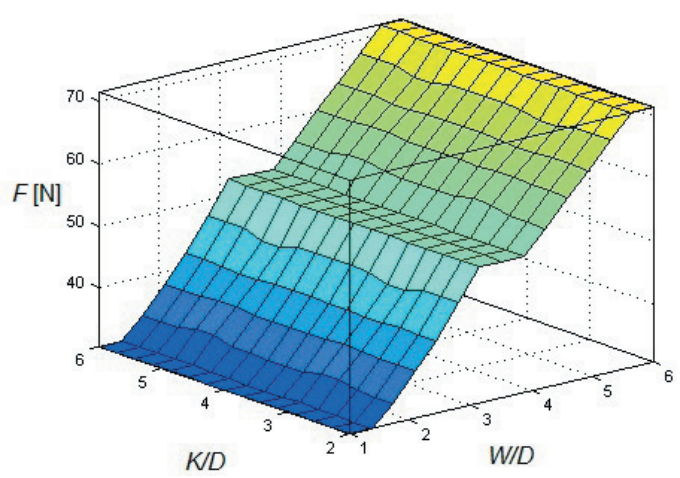

Fig. 15. Surface plot of $F$ and $W / D ; K / D$ 




Fig. 16. Surface plot of $F$ and $E / D ; M$

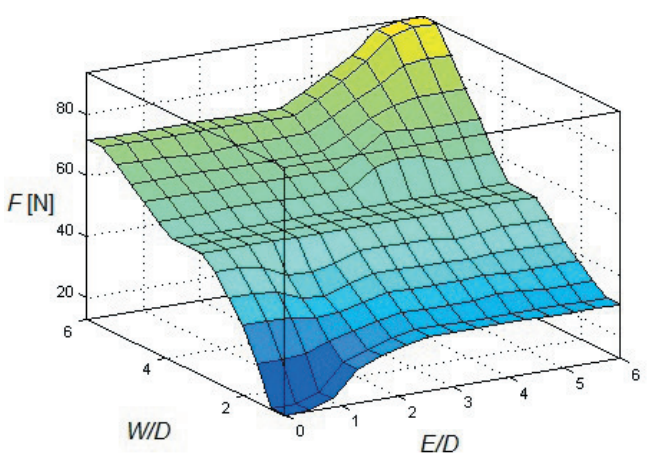

Fig. 17. Surface plot of $F$ and $E / D ; W / D$

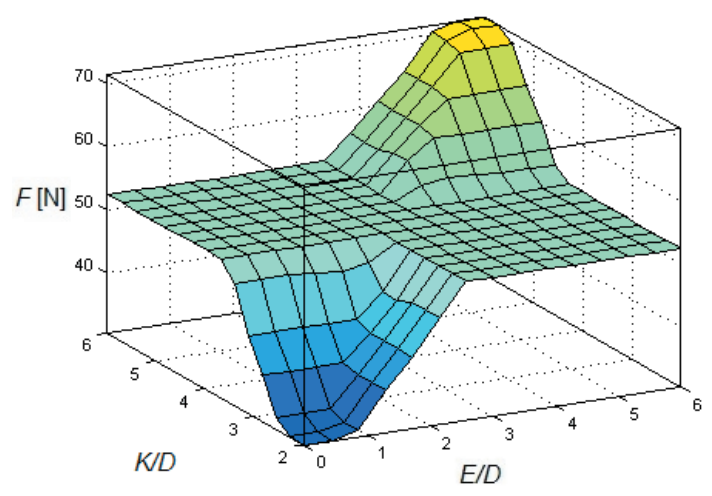

Fig. 18. Surface plot of $F$ and $E / D ; K / D$

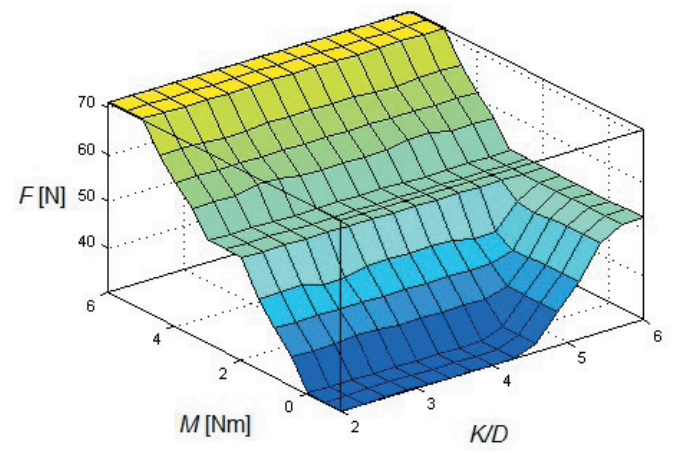

Fig. 19. Surface plot of $F$ and $K / D ; M$

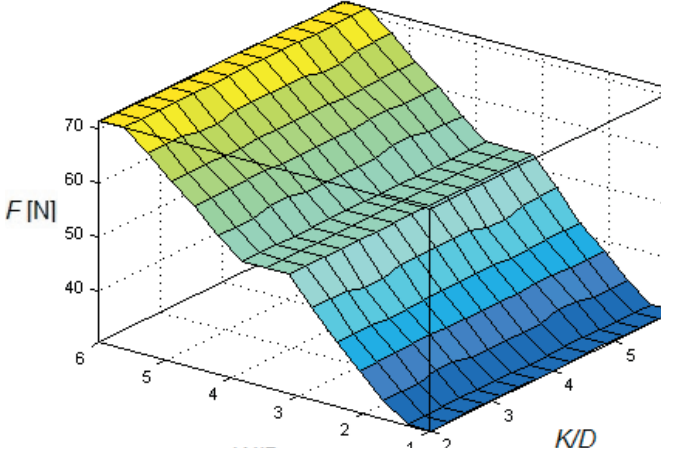

Fig. 20. Surface Plot of $F$ and $K / D ; W / D$



Fig. 21. Surface plot of $F$ and $K / D ; E / D$

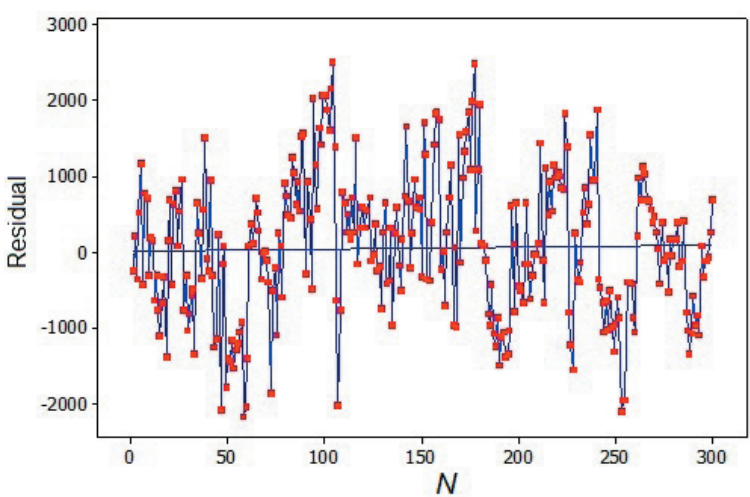

Fig. 22. Error distribution for fuzzy expert system prediction

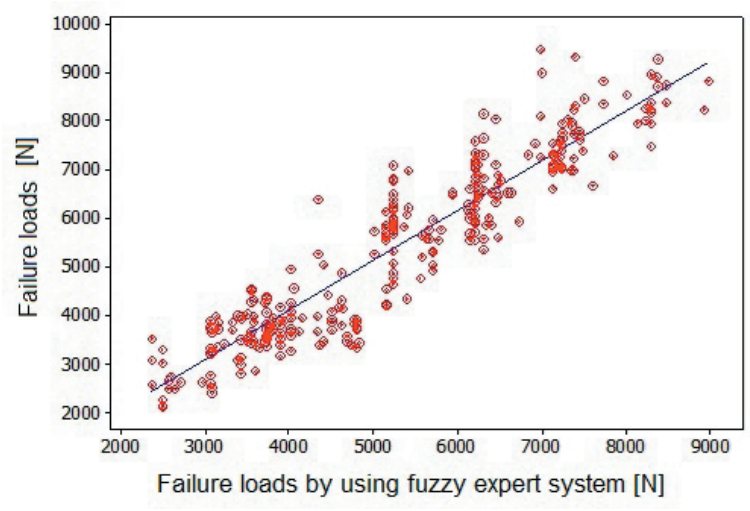

Fig. 23. Fuzzy expert system performance 
For the evaluation of the performance of both methods, the statistical parameters are presented in Table 3. These parameters are the coefficient of determination $\left(R^{2}\right)$, mean absolute deviation (MAD) and mean absolute percent deviation (MAPD) .

Table 3. Regression analysis and fuzzy expert system comparison

\begin{tabular}{lccc}
\hline & MAD & MAPD [\%] & $R^{2}$ \\
\hline Regression analysis & 827.89 & 15.19 & 0.67 \\
\hline Fuzzy expert system & 525.25 & 9.64 & 0.87 \\
\hline
\end{tabular}

MAD and MAPD values of the fuzzy expert system are lower than that of the regression analysis. This means that fuzzy expert system can model the problem well, and that its error of prediction is small. The coefficient of determination for fuzzy expert system is 0.87 . It is higher than that of the regression analysis and shows the closeness of predictions to the expected values is good.

\section{CONCLUSIONS}

In this study, a model was developed for prediction of failure loads for cross-ply laminated composite plates by using fuzzy expert system and regression analysis methods. Computational experiments were carried out to evaluate the performance of both methods. It was seen that the fuzzy expert system clearly made more efficient predictions than the regression analysis method for failure loads. The regression analysis method needs additional parameters to make better predictions in uncertain environments. The fuzzy expert system is more appropriate for the modelling of nonlinear problems and expressing uncertainty than the regression analysis method is.

This study indicates that the prediction of failure loads using fuzzy expert system is suitable for composite materials. The advantage of the present numerical study is that there are no waste materials compared to previous experimental studies. In addition, it is known that experimental studies are more expensive and need longer times for processing than computational studies.

\section{ACKNOWLEDGEMENTS}

The research is supported by Muğla Sttkı Koçman University, Turkey, BAP 2013/59.

\section{REFERENCES}

[1] Staab, G.H. (1999). Laminar Composites, $1^{\text {th }}$ ed. ButterworthHeinemann, Woburn, Massachusetts.
[2] Swanson, S.R. (1997). Introduction to Design and Analysis with Advanced Composite Materials. Prentice Hall, New Jersey.

[3] Mallick, P.K. (1993). Fiber-Reinforced Composites Materials, Manufacturing, and Design, $2^{\text {nd }}$ ed. Marcel Decker, New York.

[4] Jones, R.M. (1999). Mechanics of Composite Materials, 2th ed. Taylor \& Francis, Philadelphia.

[5] Ahn, H.S., Kweon, J.H., Choi, J.H. (2005). Failure of unidirectional-woven composite laminated pin-loaded joints. Journal of Reinforced Plastics and Composites, vol. 24, no. 7, p. 735-752, DOl:10.1177/0731684405046611.

[6] Okutan, B. (2002). The effects of geometric parameters on the failure strength for pin-loaded multi-directional fiber-glass reinforced epoxy laminate. Composites Part B: Engineering, vol. 33, no. 8, p. 567-578, D0l:10.1016/S13598368(02)00054-9.

[7] Camanho, P.P., Matthews, F.L. (1997). Stress analysis and strength prediction of mechanically fastened joints in FRP: a review. Composites Part A: Applied Science and Manufacturing, vol. 28, no. 6, p. 529-547, D0l:10.1016/ S1359-835X(97)00004-3.

[8] Wu, T.J., Hahn, H.T. (1998). The bearing strength of e-glass/ vinyl-ester composites fabricated by vartm. Composites Science and Technology, vol. 58, no. 9, p. 1519-1529, DOI:10.1016/S0266-3538(97)00180-2.

[9] Pakdil, M., Sen, F., Sayman, O., Benli, S. (2007). The effect of preload on failure response of glass-epoxy laminated composite bolted-joints with clearance. Journal of Reinforced Plastics and Composites, vol. 26, no. 12, p. 1239-1252, DOI:10.1177/0731684407079769.

[10] Ataş, A., Sen, F., Arslan, N. (2009). Failure analysis of laminated composite plates with two parallel pin-loaded holes. Journal of Reinforced Plastics and Composites, vol. 28, no. 10, p. 1265-1276, DOI:10.1177/0731684408089493.

[11] Sen, F., Sayman, O. (2009). Experimental failure analysis of two serial bolted composite plates. Journal of Applied Polymer Science, vol. 113, no. 1, p. 502-515, Dol:10.1002/app.30118.

[12] Sen, F., Komur, A., Sayman, O. (2010). Prediction of bearing strength of two serial pinned/bolted composite joints using artificial neural networks. Journal of Composite Materials, vol. 44, no. 11, p. 1365-1377, Dol:10.1177/0021998309353344.

[13] Chakraborty, D. (2005). Artificial neural network based delamination prediction in laminated composites. Materials and Design, vol. 26, no. 1, p. 1-7, Dol:10.1016/j. matdes.2004.04.008.

[14] Li, H.S., Xia, S., Luo, D.M. (2014). A probabilistic analysis for pin joint bearing strength in composite laminates using subset simulation. Composites Part B: Engineering, vol. 56, p. 780789, D0I:10.1016/j.compositesb.2013.09.025.

[15] Sen, F. (2007). Failure Analysis of Composite Pin-Loaded Joints under Preload Moments, PhD Thesis, Dokuz Eylül University, Izmir.

[16] Radojevic, D., Petrovic, S. (1997). A fuzzy approach to preference structure in multicriteria ranking. International Transactions in Operational Research, vol. 4, no. 5-6, p. 419430, DOI:10.1016/S0969-6016(97)87512-0.

[17] Zadeh, L.A. (1965). Fuzzy Sets. Information Control, vol. 8, no. 3, p. 338-353. 
[18] Lin, H.Y., Hsu, P.Y., Sheen, G.J. (2007). A fuzzy-based decisionmaking procedure for data warehouse system selection. Expert Systems with Applications, vol. 32, no. 3, p. 939-953, D0I:10.1016/j.eswa.2006.01.031.

[19] Pedrycz, W., Gomide, F. (1998). An Introduction to Fuzzy Sets: Analysis and Design. MIT Press, Cambridge.

[20] Klir, G.J., Yuan, B. (1995). Fuzzy Sets and Fuzzy Logic: Theory and Application. Prentice Hall, New Jersey.

[21] Zadeh, L.A. (1983). The role of fuzzy logic in the management of uncertainty in expert systems. Fuzzy Sets and Systems, vol. 11, no. 1-3, p. 197-198, DOl:10.1016/S0165-0114(83)800815.

[22] Zimmermann, J.-H. (1996). Fuzzy Set Theory- and Its Applications. 3 rd ed. Kluwer Academic Publishers, Norwell, Massachusetts, D0I:10.1007/978-94-015-8702-0.

[23] Dweiri, F.T., Kablan, M.M. (2006). Using fuzzy decision making for the evaluation of the project management internal efficiency. Decision Support Systems, vol. 42, no. 2, p. 712 726, Dol:10.1016/j.dss.2005.04.001.

[24] Keshwani, D.R., Jones,D.D., Meyer G.E., Brand, R.M. (2008). Rule-based mamdani-type fuzzy modeling of skin permeability. Applied Soft Computing, vol. 8, no. 1, p. 285294, D0I:10.1016/j.asoc.2007.01.007.

[25] Şen, Z. (2004). Fuzzy logic modeling principles in engineering, Water Foundation Press, Istanbul. (in Turkish)

[26] Siler, W., Buckley, J.J. (2004). Fuzzy Expert Systems and Fuzzy Reasoning, John Wiley \& Sons, Hoboken, DOl:10.1002/0471698504.

[27] Camanho, P.P., Lambert, M. (2006). A design methodology for mechanically fastened joints in laminated composite materials. Composites Science and Technology, vol. 66, no. 15, p. 3004-3020, D0l:10.1016/j.compscitech.2006.02.017. 